\title{
EFFECTS OF THE ADHD SYNDROME ON THE FREQUENCY COMPOSITION OF ERPS REVEALED BY INDEPENDENT COMPONENT ANALYSIS
}

\author{
Received September 15, 2010.
}

In this study, we investigated the frequency characteristics of independent components (ICs) of event-related potentials (ERPs) recorded in persons with attention deficit/hyperactivity disorder (ADHD) and normal adults under conditions of continuous performance test (CPT). A group of 50 participants (10 ADHD subjects and 40 ones with no attention disorders) was examined. Independent component analysis was applied to the recorded signals. For ERP extraction, averages for each group of ICs, which were time-locked to the onset of stimuli, were calculated. Several frequency characteristics (704 items) were extracted from different ERPs in each IC. Eight features of the brain signals had a significant $(P<0.001)$ correlation with the participants' clinical presentation, which is consistent with the results of previous studies. The revealed promising relation can be used for further evaluation of the sustained attention level.

Keywords: attention deficit/hyperactivity disorder (ADHD), continuous performance test (CPT), event-related potentials (ERPs), feature extraction, frequency rhythms, independent component analysis (ICA), sustained attention.

\section{INTRODUCTION}

An attention deficit/hyperactivity disorder (ADHD) syndrome is diagnosed in subjects having excessive inattentiveness, hyperactivity, and impulsivity. This disorder was primarily thought to be a problem limited to children, teenagers, and youth. However, in recent years, researchers have found that ADHD can often be a chronic phenomenon that persists into adulthood $[1,2]$. The deficiency of sustained attention, which is the core symptom in ADHD, is defined as the inability to maintain consistent behavioral responses during continuous and repetitive processing of stimuli whose non-arousing qualities would otherwise lead to habituation and distraction by other stimuli [3, 4]. In a recent study [5], it was suggested that the deficits of selective and sustained attention could cause a significant impairment of early automatic classification of the stimuli in ADHD subjects.

\footnotetext{
${ }^{1}$ Amirkabir University of Technology, Tehran, Iran.

${ }^{2}$ Tehran University of Medical Science, Tehran, Iran.

${ }^{3}$ Institute for Cognitive Science Studies (ICSS), Tehran, Iran.

${ }^{4}$ Yazd University, Yazd, Iran.

Correspondence should be addressed to F. Ghassemi

(e-mail: ghassemi@aut.ac.ir).
}

Another recent research [6] proposed that brainbased cognitive measures can support clinical decisions in ADHD cases and improve the sensitivity and specificity of the respective conclusions. Considering that event-related potentials (ERPs) are informative means for noninvasive monitoring of the brain functions, evaluation of these EEG phenomena and their analysis are considered an effective tool in neuroscience studies of such disorders, as schizophrenia, dementia, and ADHD, and also in the respective clinical applications $[1,2,7,8]$.

In several studies, ERPs and especially the P300 wave were investigated in children diagnosed with ADHD. A decrement in the amplitude of P300 developed in response to both auditory and visual stimuli was reported for ADHD children [7, 9, 10]. One of the popular tests for evaluating the level of sustained attention and, hence, ADHD is the continuous performance test (CPT) [11]. The results of ERP studies within the framework of different versions of the CPT confirmed the above-mentioned amplitude decrement in ADHD children and indicated that the corresponding medication leads to increase in the P300 amplitude [7].

Although a variety of studies was dedicated to the ERP components in ADHD children, only a few 
researchers investigated EEG phenomena in ADHD adults. A study in this regard disclosed that the ADHD group was characterized by a significantly lower absolute $\delta$ spectral power (SP) and a higher relative $\theta$ SP (across the entire scalp) than those in the control group. As to the absolute $\beta$ SP, the ADHD group had smaller values at the midline and higher powers of these oscillations in the right posterior region. These results were similar to those found in children with ADHD [12]. Another study where sustained attention was examined in normal adults during the CPT demonstrated considerable variability of the EEG rhythms [13]. As was revealed, the tested subjects shared a progressive backshift of the $\alpha$ rhythm, while the $\beta$ and $\gamma$ activities were stronger in the right than in the left hemisphere. Statistical analysis provided the evidence that EEG activity correlates with the test behavioral results in many cerebral areas.

Several studies where an independent component analysis (ICA) technique was extensively applied to ERP analysis were carried out [14-16]. The above technique is referred to the separation of independent sources (which are mixed together with an unknown mixing matrix, i.e., the mixing system and source signals are both unknown) [17]. Makeig at al. [16] used ICA for studying ERPs with estimation of various cognitive functions, such as memory or visual spatial attention. They showed that the tonic $\alpha$-band power increased in high-error epochs compared to low-error ones, while the phasic $\alpha$ power decreased briefly after the deviation onset but, then, increased strongly just before the response offset.

The approach we have pursued in our previous studies was to compare the effects of correct and wrong answers on the ERP parameters in ADHD subjects and age-matched normal participants [18]. In other studies, we classified a population of clinical ADHD cases and normal adults into three groups with different levels of attention. A promising accuracy (above $80 \%$ ) was acquired [14, 19 ], encouraging us to develop the number of classes for further studies.

In this study, we examined the frequency characteristics of independent components (ICs) of ERPs for ADHD and normal adults while performing a CPT. Also, the quantitative analysis of ERP frequency variations in normal and ADHD participants was provided using Pearson correlations between the sustained attention level of the participants and the defined frequency features.

\section{METHODS}

Participants. Signals recorded in 50 volunteers were used for the analysis. Informed consent was obtained from each participant after explaining the protocol. The experiment was conducted in accordance with the Declaration of Helsinki. The review board of the Institute for Cognitive Science Studies (ICSS) also revised and approved the experimental protocol. The mean age of the participants was $29.78 \pm 6.15$ years. Fifty-two percent of the group were men. All 50 participants were examined for handedness using the Edinburgh test, and they were found to be righthanded. They had normal or corrected-to-normal vision and were checked for color blindness by the Ishihara test, which revealed that two participants were colorblind. According to the interview by a psychiatrist, 10 participants $(29.8 \pm 6.4$ years, 7 men $)$ suffered from ADHD (inattention sub-type). The conclusions were based on the Diagnostic and Statistical Manual of Mental Disorders, 4th edition, DSM-IV [2]. The diagnosis was confirmed by the results of the self-report screening form of the Conners' Adult ADHD Rating Scale (CAARS-S: SV) [20]. Other 40 participants had no major psychiatric or medical disorders. All tested subjects used no medications.

Recording Procedure. The second version of Conners' CPT [11] was used in this study; this is a "nogo" CPT task. Different letters of the English alphabet were presented randomly on the screen of a monitor, and participants were asked to click the left mouse button with the index finger of their dominant hand when any letter except for the target " $X$ " appeared. Participants were instructed to respond as fast as they could and as accurately as possible.

There were six testing blocks, with three sub-blocks in each containing 20 trials. Therefore, the experiment involved presentation of 360 stimuli, where there were $36 \mathrm{X}$ letters (no-go stimuli) and 324 other letters (go stimuli). The interstimulus intervals (ISIs) were 1, 2, or $4 \mathrm{sec}$ with a display time of $250 \mathrm{msec}$. Different ISIs were presented in a randomized order.

The participants set on a comfortable chair with a place for relaxing the head. The test was performed in a quiet and dimly-lit room. The distance between the participant's eyes and a 19-inch monitor was $75 \pm 5 \mathrm{~cm}$ depending on the height of the subject. The letters were $7.5 \mathrm{~cm}$ high and $7 \mathrm{~cm}$ wide, which resulted in a $7 \mathrm{deg}$ visual angle. They appeared white-colored on a black background. A short practice test $(70 \mathrm{sec})$ was performed before conducting the full test, to ensure 
that the participant has fully understood the task. Each test took approximately $14 \mathrm{~min}$ to complete.

The EEG samples were recorded using $19 \mathrm{Ag} / \mathrm{AgCl}$ electrodes mounted in an electrode cap and placed according to the international 10-20 standard. The impedance of all electrodes was kept below $5 \mathrm{k} \Omega$. The average of $\mathrm{A} 1$ and $\mathrm{A} 2$ was used as the reference. A bipolar vertical EOG was also recorded. Two additional bipolar channels were used for synchronization of the CPT system with EEG signals and recording of participants' responses. A 32-channel AC/DC amplifier (Walter Graphtek, Germany) was used for data recording, and Pl-Winsor 3.0 software was used for data acquisition. The amplifier bandpass was 0.05 to $100 \mathrm{~Hz}$, and a $50-\mathrm{Hz}$ notch filter was used for line noise reduction. The sampling rate was $200 \mathrm{sec}^{-1}$.

Preprocessing. The data obtained were analyzed using MATLAB 2009a software (MathWorks, USA). A suitable bandpass filter $(0.1-80 \mathrm{~Hz})$ was used to eliminate movement artifacts and a $50-\mathrm{Hz}$ notch filter to suppress the remaining line noise. The ICA was initially performed for canceling EOG artifacts $[21,22]$. A combination of the Efficient variant of Fast ICA (EFICA) and Efficient Weight-Adjusted SOBI (EWASOBI) was chosen as the ICA method and realized using ICALAB software [23]. The ICs are identifiable up to a permutation and scaling of the sources [17]. The EOG components were automatically recognized by calculating the correlation between the recorded EOG and all components achieved by ICA. The component with a correlation coefficient (CC) greater than 0.8 (with the $P$ value below 0.01 ) was classified as the EOG component. This component was eliminated, and then all other components were back-projected to their initial space. Then, artifactual parts of EEG, including abnormal values, trend, and spectra, and also improbable data, were automatically rejected using EEGLAB software [24]. The ICA was again applied to cleaned EEG. Regarding the permutation ambiguity in the ICA methods, definition of equivalent ICs in different participants should be considered. For each participant, correlation of each IC recorded by all scalp electrodes was calculated. The channel with the greatest CC (greater than 0.8 , the $P<$ $<0.01$ ) was considered to have the most effect of that IC on the scalp. Then, ICs of different participants with the most effects clearly pronounced at similar distinct scalp electrodes were considered to be equivalent. For 1200-msec-long epoch extraction periods, 200-mseclong pre-stimulus and 1,000-msec-long post-stimulus intervals were considered. The baseline was calculated by averaging of a 200 -msec-long segment prior to the stimulus onset and subtracted from the epoch. Artifactfree epochs extracted from each group, which were time-locked to the stimulus onset, were averaged to calculate the ERP parameters.

Feature Extraction. Several frequency features were defined and evaluated in different groups (ISIs and blocks yielding in 704 features; 8 features $\times 4$ ERP groups $\times 22$ cases for each IC described below). These features have shown to have adequate performances in a few similar studies $[7,14,18,19,25]$ and, hence, were believed to be useful for application in our tests.

Frequency Features. The powers of the signal within five different frequency bands $(\delta, \theta$ to $4 \mathrm{~Hz} ; \theta, 4$ to $8 \mathrm{~Hz} ; \alpha, 8$ to $13 \mathrm{~Hz} ; \beta, 13$ to $30 \mathrm{~Hz}$; and $\gamma>30 \mathrm{~Hz}$ ) were considered the defined features in addition to the mean, median, and modal frequencies. The mean frequency represents the centroid of the spectrum and is calculated from the weighted averaging of the frequencies within the power spectral density (PSD) of the signal. The median frequency separates the power spectrum into two equal energy areas. The modal frequency is the frequency with the greatest energy content in the signal spectrum. So, the maximum amplitude in the PSD of the signal is observed at this frequency.

ERP Groups. Four groups of ERPs were considered for each case. These were potentials related to the target stimuli (X), non-target stimuli (nX), correct answers to the target stimuli (CX, i.e., the $X$ that the participant did not respond to), and wrong answers to the target stimuli (WX). Each group was averaged separately for ERP extraction.

ERP Cases. Twenty-two different cases were considered.

a) Total signal (1). The whole signal was considered as a separate case.

b) ISI cases (6). Three different ISIs (ISIs of 1, 2, or $4 \mathrm{sec}$ ) were considered separately. Also, the ISIs relative to each other were considered as three additional cases.

c) Block cases (15). Six time windows were considered in order to investigate the ERP changes in time. Each window was $155 \mathrm{sec}$ long and contained three different ISI subblocks. The width of the window was calculated in such a way that all blocks contained the same number of targets. Also, nine relative cases were considered (each block relative to previous one and all blocks relative to the first block) to compare the differences between blocks.

Symbols A, D, and $\mathrm{M}$ are used, respectively, 
for the mean, median, and modal frequencies. The power in each frequency rhythm is indicated by the corresponding symbol. The phrase in the parentheses explains the group, and subscript indices express the related ISI or the block of calculated ERPs, which could be absolute or relative. For example, $\mathrm{M}_{\mathrm{B} 3} \mathrm{WX}\left(\mathrm{IC}_{10}\right)$ means the modal frequency for the ERP calculated for the 3 rd block in the wrong $X$ group in the 10 th IC, or $\delta_{\mathrm{S42}} \mathrm{nX}\left(\mathrm{IC}_{11}\right)$ means the difference between the $\delta$ powers for the ERPs calculated for 2- and 4-sec-long ISIs in the non-X group in the 11 th independent component.

Data Processing. Regarding the behavioral data, the repeated-measure analysis of variance (ANOVA) was performed on (1) the hit reaction time (HRT, mean response time for all non-X responses), (2) omissions (number of non-targets to which the participant did not respond), (3) commissions (number of times the participant erroneously responded to the target "X"), and (4) HRT standard error (HRT s.e., standard error for the responses to non-X stimuli) for the class of participants, ADHD vs normal adults (hereafter, class), which was considered a between-subject factor.

Regarding the ERP data, repeated-measure ANOVAs were performed between the ERP data, and repeated-measure ANOVAs were performed between the ERP-frequency features and class. Only significant effects $(P<0.001)$ are reported. For investigating the relation between the defined features and class of the participants, Pearson correlation was calculated. Only features with $P$ values below 0.001 were considered significant.

\section{RESULTS}

Behavioral Data. The mean HRTs in the normal and ADHD groups (mean \pm s.d.) were $372.8 \pm 48.2$ and $370.9 \pm$ $\pm 33.4 \mathrm{msec}$, respectively. The average of Omissions in both normal and ADHD groups was $0.4 \%$, while the averages of Commissions in these groups were 30 and $40 \%$, respectively. The mean age in the normal group was $29.78 \pm 6.1$ years, which nearly precisely coincides with that in the ADHD group $(29.8 \pm 6.4$ years). In the normal group, $47.5 \%$ of the participants were man, while in the ADHD group this percentage was $70 \%$. No reliable difference was found between ADHD and normal participants for the behavioral data, as is mentioned in Table 1.

Data of the ERPs. Figure 1 represents the grandaverage PSD of ERPs recorded in normal and ADHD participants. The PSDs for all ICs were averaged within
T a b l e 1. Results of ANOVAs Performed for Behavioral Data between ADHD-Suffering and Normal Participants

T а б л и ц я 1. Результати застосування ANOVA щодо різниць поведінкових проявів у нормальних обстежених та осіб з ADHD-синдромом

\begin{tabular}{l|l|l|l}
\hline $\begin{array}{l}\text { Ordinal } \\
\text { number }\end{array}$ & \multicolumn{1}{|c|}{ Behavioral Data } & F $(1,49)$ & $P$ value \\
\hline 1 & HRT & 0.02 & 0.8848 \\
2 & Omission & 0.02 & 0.8770 \\
3 & Commission & 2.35 & 0.1318 \\
4 & HRT s.e. & 2.16 & 0.1478 \\
\hline
\end{tabular}

Footnotes: HRT) Hit reaction time; ADHD) attention deficit/ hyperactivity disorder. For details, see Methods.

T a b l e 2. Results of ANOVAs Performed for the Eight Behavioral Extracted Features between ADHD-Suffering and Normal Participants

T а б л и ц я 2. Результати застосування ANOVA щодо восьми визначених поведінкових особливостей у нормальних обстежених та осіб з ADHD-синдромом

\begin{tabular}{l|c|c|c|c}
\hline $\begin{array}{c}\text { Ordinal } \\
\text { number of } \\
\text { the defined } \\
\text { feature }\end{array}$ & $\begin{array}{c}\text { ERP frequency } \\
\text { feature }\end{array}$ & $\mathrm{F} \mathrm{(1,49)}$ & $P$ value & $\begin{array}{c}\mathrm{R} \\
\text { (Pearson) }\end{array}$ \\
\hline 1 & $\delta_{\text {Total }} \mathrm{CX}(\mathrm{IC} 12)$ & 17.83 & 0.0001 & 0.52 \\
2 & $\delta_{\mathrm{B} 54} \mathrm{CX}(\mathrm{IC} 8)$ & 17.5 & 0.0001 & -0.52 \\
3 & $\gamma_{\mathrm{B} 43} \mathrm{X}(\mathrm{IC} 4)$ & 16.56 & 0.0002 & 0.51 \\
4 & $\alpha_{\mathrm{S} 2} \mathrm{nCX}(\mathrm{IC} 15)$ & 14.12 & 0.0005 & 0.48 \\
5 & $\mathrm{D}_{\mathrm{B} 61} \mathrm{nCX}(\mathrm{IC} 7)$ & 13.62 & 0.0006 & 0.47 \\
6 & $\alpha_{\mathrm{S} 21} \mathrm{nCX}(\mathrm{IC} 15)$ & 13.56 & 0.0006 & 0.47 \\
7 & $\mathrm{M}_{\mathrm{B} 2} \mathrm{X}(\mathrm{IC} 14)$ & 12.47 & 0.0009 & 0.45 \\
8 & $\mathrm{D}_{\mathrm{B} 65} \mathrm{X}(\mathrm{IC} 18)$ & 12.35 & 0.0010 & 0.45 \\
\hline
\end{tabular}

Footnotes. Only features with $\mathrm{P}<0.001$ are reported. ERP) Eventrelated potential. For details, see Methods

each group. The grand-average PSD demonstrated prominent peaks at a $10 \mathrm{~Hz}$ frequency ( $\alpha$ band) for both normal and ADHD participants.

An ANOVA was performed between each extracted feature and the class, which revealed that a main significant $(P$ value $<0.001)$ effect of the class can be observed in eight features, which are described in Table 2. Quantitative analysis of ERP variations in normal and ADHD participants was provided using Pearson correlations between the participant class and the defined features. It is noteworthy that only the $P$ values for the same eight features were less than 0.001 , and their CC are reported. Table 2 indicates that the greatest value of the $\mathrm{CC}$ is 0.52 , which correspond to $\delta_{\text {Total }} \mathrm{CX}\left(\mathrm{IC}_{12}\right)$ and $\delta_{\mathrm{B} 54} \mathrm{CX}\left(\mathrm{IC}_{8}\right)$. Both these features 


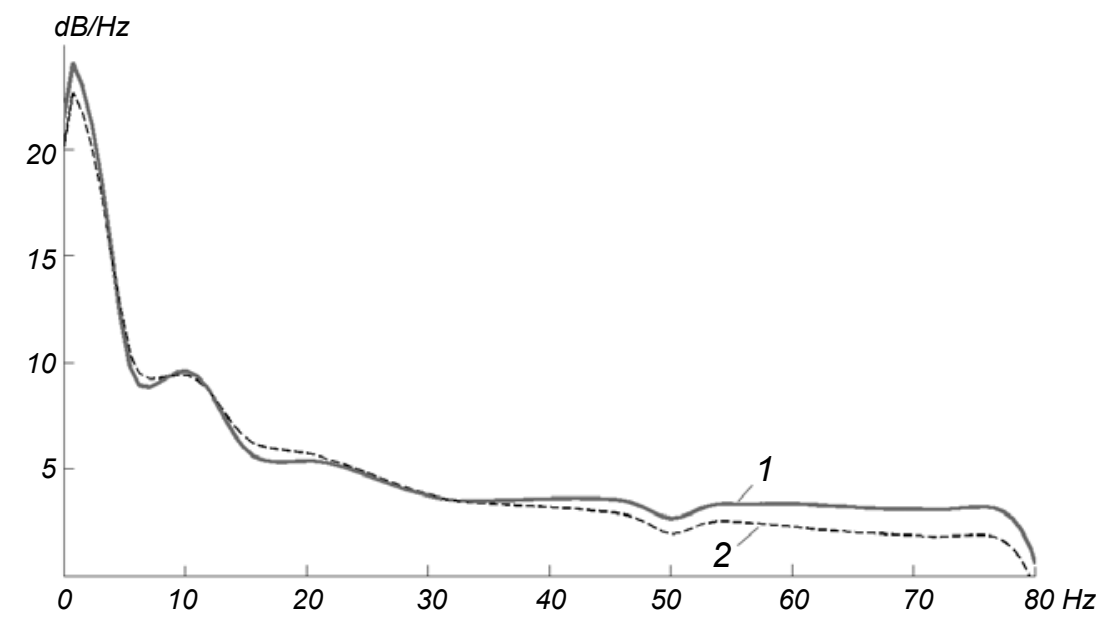

Grand-average distribution of the power spectral densities (PSDs) of event-related potentials recorded in normal (1) and ADHD (2) participants.

Загальноусереднені розподіли спектральної щільності потужностей для пов'язаних 3 подією потенціалів, зареєстрованих у нормальних обстежених (1) та тестованих 3 наявністю синдрому дефіциту уваги (2) та гіперактивності.

are related to the power within the $\delta$ range for correctanswered ERP. The former was extracted from the total signal of the 12 th IC, while the latter showed the difference between the $\delta$ power in the 4th and 5 th blocks of the 8 th IC. It should be noted that signs for these features of the CCs are opposite, which means that while $\delta_{\text {Total }} \mathrm{CX}\left(\mathrm{IC}_{12}\right)$ increases with the class characteristics, $\delta_{\mathrm{B} 54} \mathrm{CX}\left(\mathrm{IC}_{8}\right)$ decreases.

\section{DISCUSSION}

In several studies, ICA was applied for ERP analysis [14-16]. Extraction of some characteristics of the brain signals in IC domain, such as shape features, improved the evaluation and classification results for ADHD patients, which persuade us to investigate ADHD effects on the frequency rhythms of ERP-independent components.

It can be observed from the grand-average PSDs that the power within the $\alpha$ range for ADHD participants is samewhat lower than that in the normal group. At the same time, the powers in the $\delta$ and $\gamma$ bands are also lower than those in the normal participants. These findings in the IC domain are in agreement with the findings of previous studies in the time domain $[5,12,13,16]$.

The correlations calculated confirm the existence of significant relations between the participants' clinical characteristics and some frequency features of the respective ERPs. It was found that eight of the defined features represent the main effect of the participant class. The considered threshold for the $P$ value is 0.001 , which makes the achievements very reliable. Regarding the significant features, five of them were extracted from time blocks, while $80 \%$ of them were related to the comparison of two blocks. This is consistent with the design of the CPT protocol for measuring the sustained attention during time blocks. All of the significant features were related to the target stimuli ( $3 \mathrm{X}, 3 \mathrm{WX}$, and $2 \mathrm{CX}$ ). Regarding the power in different frequency ranges, five of the significant features were related to the powers of the $\delta, \alpha$, and $\gamma$ bands.

In this study, different frequency characteristics of ICs of ERPs were extracted and compared; ERPs were recorded while adult participants resolved a continuous performance task. The normal and ADHD groups of subjects were investigated separately. The results obtained revealed that there is a significant correlation $(P<0.001)$ between clinical characteristics of the participants and defined features from ICs of the EEG signals.

Consequently, the results obtained represent a significant relation between clinical presentation of the participants and several extracted features from the ICs of brain signals. Therefore, the implementation of ERP and ICA for further studies on the ADHD and sustained attention disorders is validated.

Acknowledgments. The authors are thankful to the Institute for Cognitive Science Studies (ICSS) for providing the EEG laboratory for performing the tests, and to Dr. Anahita Khorrami and Eng. Amin Mohammadian for their assistance in designing the protocol and conducting the test for some participants. The authors also thank all participants for their contribution to this study. 
Ф. Гассемі ${ }^{1}$, М. Х. Мораді ${ }^{1}$, М. Техрані-Доост ${ }^{2,3}$, В. Абуталебі ${ }^{4}$

\section{ВПЛИВИ СИНДРОМУ ДЕФІЦИТУ УВАГИ ТА ГІПЕРАКТИВНОСТІ НА ЧАСТОТНУ КОМПОЗИЦІЮ ППП, ВИЯВЛЕНІ ЗА ДОПОМОГОЮ АНАЛІЗУ НЕЗА- ЛЕЖНИХ КОМПОНЕНТІВ}

\author{
${ }^{1}$ Технологічний університет Аміркабір, Тегеран (Іран). \\ ${ }^{2}$ Тегеранський медичний університет (Іран). \\ ${ }^{3}$ Інститут досліджень пізнавальної здатності, Тегеран (Іран). \\ ${ }^{4}$ Університет Йєзда (Іран). \\ Р е 3 ю м е
}

У роботі вивчали частотні характеристики пов'язаних 3 подією ЕЕГ-потенціалів (ППП) у дорослих тестованих 3 наявністю синдрому дефіциту уваги й гіперактивності (ADHD) та його відсутністю (норма) в умовах тесту безперервного виконання (continuous performance test, CРТ). Дослідження були проведені на 50 добровольцях (10 тестованих 3 наявністю ADHD i 40 практично здорових людей). Для вивчення ППП використовували методику незалежного компонентного аналізу. Середні величини для кожної групи незалежних компонентів (НК), „прив' язаних” до моменту пред'явлення стимулу, розраховували, щоб описати ППП. У кожному НК у складі різних ППП було виділено низку частотних особливостей (усього 704 риси). Як виявилося, вісім таких рис досліджуваних ППП вірогідно $(P<$ $<0.001)$ корелювали 3 клінічними характеристиками тестованих, що узгоджується з результатами, отриманими в попередніх роботах. Наші дані можуть бути використані для об'єктивної оцінки рівня підтримуваної уваги.

\section{REFERENCES}

1. C. K. Conners, D. Erhardt, and E. Sparrow, Conners' Adult ADHD Rating Scales (CAARS), Multi-Health Systems Inc., New York (1999).

2. H. R. Searight and J. M. Burke, "Adult attention deficit hyperactivity disorder," in: Up To Date 17.1, 2009, T. L. Schwenk and H. N. Sokol (eds.). Available from: http://www.uptodate.com/home/about/index.html.

3. E. Kandel, J. Schwartz, and T. Jessell, "Principles of neural science," in: Visual Attention, McGraw-Hill (2000).

4. I. H. Robertson, T. Manly, J. Andrade, et al., "Oops!: Performance correlates of everyday attentional failures in traumatic brain injured and normal subjects," Neuropsychologia, 24, 636-647 (1997).

5. D. Lenz, K. Krauel, H. Flechtner, et al., "Altered evoked gamma-band responses reveal impaired early visual processing in ADHD children," Neuropsychologia, 48, 1985-1993 (2010).

6. L. M. Williams, D. F. Hermens, T. Thein, et al., "Using brainbased cognitive measures to support clinical decisions in ADHD," Pediat. Neurol., 42, 118-126 (2010).

7. R. J. Barry, A. R. Clarke, R. McCarthy, et al., "Event-related potentials in two DSM-IV subtypes of attention-deficit/ hyperactivity disorder: an investigation using a combined modality auditory/visual oddball task," in: Attention-Deficit/ Hyperactivity Disorder (AD/HD) and the Hyperkinetic Syndrome (HKS): Current Ideas and Ways Forward,
R. D. Oades (ed.), Nova Publishers, New York (2006), pp. 229-247.

8. M. Arns, S. Ridder, U. Strehl, et al., "Efficacy of neurofeedback treatment in ADHD: the effects on inattention, impulsivity and hyperactivity: a meta-analysis," J. Clin. EEG Neurosci., 40, 180-190 (2009).

9. C. C. Duncan, R. J. Barry, J. F. Connolly, et al., "Eventrelated potentials in clinical research: Guidelines for eliciting, recording, and quantifying mismatch negativity, P300, and N400," Clin. Neurophysiol., 120, 1883-1908 (2009).

10. R. J. Barry, S. J. Johnstone, and A. R. Clarke, "A review of electrophysiology in attention-deficit/hyperactivity disorder: II. Event-related potentials," Clin. Neurophysiol., 114, 184198 (2003).

11. C. K. Conners and MHS Staff, Conners' Continuous Performance Test II (CPT II), Ver. 5, Multi-Health Systems, Canada (2004).

12. A. R. Clarke, R. J. Barry, P. C. Heaven, et al., "EEG in adults with attention-deficit/hyperactivity disorder," Int. J. Psychophysiol., 70, 176-183 (2008).

13. E. Molteni, A. M. Bianchi, M. Butti, et al., "Analysis of the dynamical behavior of the EEG rhythms during a test of sustained attention," in: Proceedings of the 29th Annual International Conference of the IEEE/EMBS, Cité Internationale, France (2007), pp. 1298-1302.

14. A. Hyvarinen, J. Karhunen, and E. Oja, Independent Component Analysis - Theory and Applications, John Wiley \& Sons, London, New York (2001).

15. F. Ghassemi, M. H. Moradi, M. Tehrani-Doost, and V. Abootalebi, "Classification of sustained attention level based on morphological features of EEG's independent components," in: Proceedings of the IEEE/ICME International Conference on Complex Medical Engineering (CME 2009), Tempe, AZ, USA (2009), pp. 1-6.

16. J. D. Kropotov and V. A. Ponomarev, "Decomposing N2 NOGO wave of event-related potentials into independent components," NeuroReport, 20, 1592-1596 (2009).

17. R. Huang, T. Jung, A. Delorme, et al., "Tonic and phasic electroencephalographic dynamics during continuous compensatory tracking," NeuroImage, 39, 1896-1909 (2008).

18. F. Ghassemi, M. H. Moradi, M. Tehrani-doost, and V. Abootalebi, "Effects of correct and wrong answers on ERPs recorded under conditions of the continuous performance test in ADHD/normal participants," Neurophysiology, 42, No. 3, 255-262 (2010).

19. F. Ghassemi, M. H. Moradi, M. Tehrani-Doost, and V. Abootalebi, "Combination of independent component analysis and feature extraction of ERP for level classification of sustained attention," Proceedings of the 4th International IEEE/EMBS Conference on Neural Engineering (NER), Antalya, Turkey (2009), pp. 136-139.

20. C. K. Conners, D. Erhardt, and E. P. Sparrow, Conners 'Adult ADHD Rating Scales (CAARS), Multi-Health Systems, Canada (2002).

21. A. Delorme, T. Sejnowski, and S. Makeig, "Enhanced detection of artifacts in EEG data using higher-order statistics and independent component analysis," NeuroImage, 34, 14431449 (2007).

22. S. Vorobyov and A. Cichocki, "Blind noise reduction for multisensory signals using ICA and subspace filtering, with application to EEG analysis," Biol. Cybern., 86, 293-303 (2002).

23. http://www.bsp.brain.riken.jp/ICALAB/

24. http://www.scen.ucsd.edu/eeglab/

25. V. Abootalebi, M. H. Moradi, and M. A. Khalilzadeh, "A new approach for EEG feature extraction in P300-based lie detection," Computer Methods Programs Biomed., 4, 48-57 (2009). 